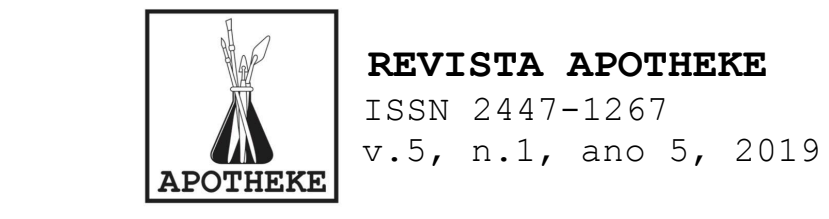

\title{
Criação, Experiência E Compartilhamentos - O Ser E Estar Artista Professor.
}

\author{
André Rigatti (FBAUP/UNIR)
}

\begin{abstract}
RESUMO: Este ensaio inserido no debate em torno do tema "Artista Professor - ser e estar", reúne diversas reflexões pessoais sobre o tema, considerando também a experiência deste pesquisador como ponto de partida. No cerne desta questão, a reflexão a ser desenvolvida deverá seguir o ser e estar deste artista/professor, indagando o que significa ser um e outro, ou apenas ser em tempo integral, sou ou estou artista/professor?
\end{abstract}

PALAVRAS-CHAVE: artista/professor; arte contemporânea; criação; experiência; ensino.

ABSTRACT: This essay, inserted in the debate around the theme "Artist Professor - be and being", brings together several personal reflections on the theme, also considering the experience of this researcher as a starting point. At the core of this question, the reflection to be developed should follow the be and being of this artist/professor, asking what it means to be one and the other, or just being full-time, am I or I am being an artist / professor?

KEYWORDS: artist/professor; contemporary art; creation; experience; teaching .

Inicialmente, quando pensamos no binômio artista/professor, cria-se a imagem de um duplo profissional, - que de certa forma, não deixa de ser apropriado. Por outro lado, alguns exemplos nos mostram um profissional totalmente integrado entre as duas áreas, com atuações que se mesclam fluidamente, e que quase não se percebe mais quando o mesmo está a atuar como artista ou como professor.

Sabemos em nossa história recente, de inúmeros artistas historicamente estabelecidos que desenvolveram suas carreiras artísticas aliadas a sua prática como docentes, dentre eles, Paul Klee, Joseph Beuys, Luciano Fabro, Iberê Camargo, Guido Viaro, Nelson Leirner, Ricardo Basbaum, Sérgio Romagnolo, entre tantos outros. Alguns ligados a universidades, em cursos de graduação e pós-graduação, outros em ateliês públicos, ou 


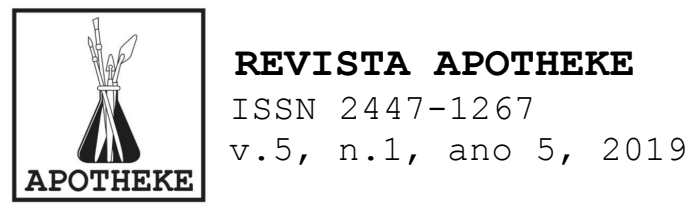

em seus próprios estúdios de trabalho. Mas o que move o artista a transitar entre a criação e o ensino?

É fato, que a grande qualidade de uma escola de arte (tanto no ensino formal como informal), está na possibilidade de propiciar múltiplas saídas profissionais, ofertando um vasto repertório carregado de diferentes maneiras de compreender o universo da arte. Fornecendo a possibilidade de escolha aos estudantes para que optem livremente em qual lugar do campo artístico irão atuar, seja dentro de uma das diversas linguagens artísticas, seja no campo teórico ou pedagógico.

No ínterim deste patamar, como coloca Bernardo Pinto Almeida (2017: 95), é necessário considerar a presença do artista no ambiente de ensino, (de múltiplos artistas na verdade) que tragam suas experiências específicas para o ensino de cada uma das linguagens artísticas, assim como para a teoria e história da arte, criando um entrecruzamento de saberes. Para enfim, proporcionar a livre circulação dos estudantes entre diversos pontos de vista, com a possibilidade de se depararem com optações que os direcionarão para o campo profissional.

Como artista e, posteriormente como professor, pude perceber no campo da própria experiência, a importância de se ter um ambiente de ensino formado pela constante presença de múltiplos artistas, seja na graduação, no mestrado e por ora no doutoramento. Quando ingressei na graduação em Artes Visuais, tinha muito clara a opção pela atuação como artista. No entanto, tive a sorte de perceber alguns exemplos, onde o professor/artista, não desempenhava um duplo papel totalmente diferenciado entre uma atuação e outra. Em muitos casos, não se percebia a diferença, pois mesmo no ambiente de ensino observava que criavam e ensinavam ao mesmo tempo. Essa experiência, de certa forma, me motivou a continuar com minha intenção de ser um artista, mas, alimentou meu desejo de ser 


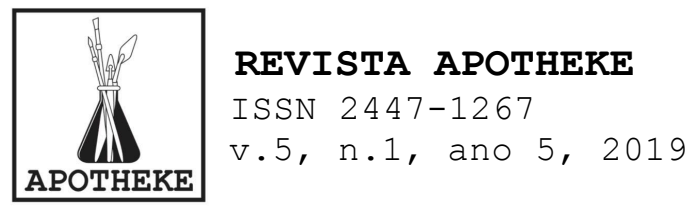

também professor, o que veio a se concretizar alguns anos depois de minha graduação.

Hoje, sendo artista e professor, não intenciono ser este exemplo para meus alunos, e sim, projetar neles a possibilidade de compreensão de uma certa fluidez entre um papel e outro, e de como o ser artista alimenta o ser professor e vice versa. Sendo o exercício da criação uma possível ferramenta didática, assim como, a formulação de aprendizagens por projetos de trabalho como ferramentas criativas.

Em diversos momentos como artista e professor, pude perceber a contaminação de meu exercício criativo no planejamento de minhas atividades como docente, e vice-versa. Em minha investigação no campo da pintura, muitas vezes, me deparei com descobertas cromáticas, espaciais, matéricas, teóricas, estéticas ou históricas, entre outras, que me levaram automaticamente a formular projetos de trabalho com os estudantes para dividir e explorar com eles diversos encontros e desencontros que a investigação artística pode oferecer, e desses projetos desenvolvidos em sala de aula, muitos dos resultados implicaram diretamente em minhas escolhas enquanto artista investigador. E o resultado desse trânsito é um ir e vir de práticas que se fundem, se alimentam e ampliam o horizonte de atuação profissional.

Com os estudantes desenvolvi projetos de trabalho, onde as decisões de como e o que pesquisar eram tomadas em conjunto. Definíamos primeiramente os problemas que cada um deles poderiam trazer como ponto de partida para suas criações, e destes problemas seriam escolhidos os meios e linguagens adequadas para desenvolver a investigação. Todo o processo partia do indivíduo criador/investigador, assim como do artista/professor, figura presente na reflexão e na adição de sentidos. As escolhas reverberavam nas decisões do 


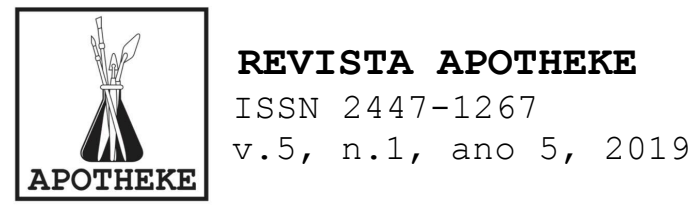

coletivo, num leve deixar contaminar-se e contaminar. Essa contaminação entre os estudantes inegavelmente me afetava, e eu, como professor, me colocava neste lugar, e levava daqui importantes reflexões para minha prática como professor e para minha investigação como artista. Por detrás desta prática me ancorava em reflexões provenientes da história da arte, do contexto da pintura e da investigação artística. No entanto, foi através da reflexão do educador espanhol Fernando Hernandéz, que encontrei um eco impulsionador para desenvolver esta prática de trabalho baseada em projetos, onde todos nos deixávamos contaminar de forma livre e despretensiosa.

Assim, a sistematização do processo de ensino e aprendizagem se baseou em criar um projeto de trabalho, onde reconhecíamos a necessidade de criar uma organização das atividades de forma não linear, e começamos a refletir na possibilidade de construirmos pensamentos helicoidais, promovendo as tais mútuas contaminações no processo criativo, relacionando diferentes fontes de conhecimento, que partiam do artista/professor, dos estudantes e das demais fontes de referência, considerando sempre as influências do cotidiano de cada um. Intencionávamos estabelecer projetos de criação, onde - ponto de partida era estabelecido em conjunto, e o desenvolvimento, assim como o ponto de chegada, anunciavam a necessidade de continuar seguindo, pois o trabalho criativo se apresentava como um gesto após o outro, intermitente e fortificado em cada ação, em cada passo. Uma ação que pede a continuidade, sempre, e nunca uma finalização enraizada. "Todo ponto de chegada constitui em si um novo ponto de partida" (HERNÁNDEZ, 1998: 48).

Por esta via, percebíamos notoriamente, que a criação desenvolvida como um projeto, amplo, compartilhado e contaminado, era capaz de se tornar uma potente ferramenta didática aos futuros professores/artistas que ali estavam em 


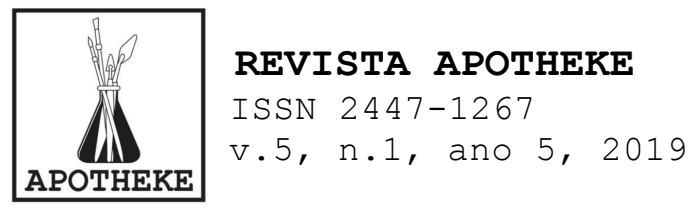

formação. Pois exercitamos nossas capacidades de escolha e o desenvolvimento de olhares críticos, mas acima de tudo, nossa potencialidade em problematizar a própria realidade, assim como aquela externa que nos circundava. Avaliávamos a intenção de cada um, a preparação, a execução e por fim a apreciação em conjunto dos resultados obtidos individualmente. Neste processo, percebi claramente como minha atuação como artista contribuiu em minha prática docente, e como os trabalhos desenvolvidos e todas as etapas citadas influenciaram em minha investigação como artista.

Desta forma, coletivamente, percebemos que projetos de trabalho como estes, que desenvolvi de 2014 a 2018, na Universidade Federal de Rondônia, no âmbito do curso de Licenciatura em Artes Visuais, são processos contínuos que contribuem significativamente tanto para o processo do artista como para o planejamento do professor. Refletindo assim, concepções de conhecimento como produção coletiva, onde experiência e produção se enredam, originando aprendizagens construidas que possibilitam uma maleabilidade entre o ir e vir de um profissional que não é apenas artista e professor, é por sim, um híbrido em sua atuação.

Ao mesmo tempo, associávamos o pensamento filosófico de John Dewey, que trata da arte como experiência, apontando a necessidade de se criar uma relação entre os trabalhos de arte desenvolvidos durante os projetos, enquanto possíveis formas de experenciar práticas reais. Pois os projetos de trabalho propiciavam um conjunto de acontecimentos e vivências compartilhadas que reverberavam intensamente sobre cada um durante o processo, constituindo de fato, exemplares claros de uma experiência concreta e 


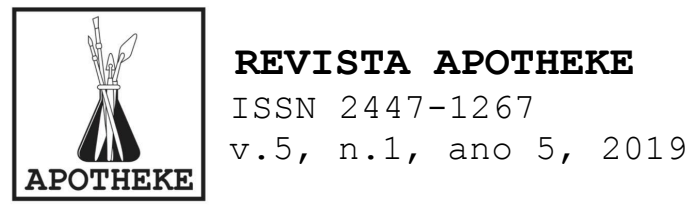

sensível. E a cada passo dado se construíam novas experiências de vida, compostas pela hibridização entre reflexão e materialização. Pois o processo de investigar em Arte é beirar o desconhecido, é desafiarse, é ter a experiência de viver conciliando razão e emoção, escrita e produção, materialidade e reflexão.

\begin{abstract}
A experiência ocorre continuamente, porque a interação do ser vivo com as condições ambientais está envolvida no próprio processo de viver. Nas situações de resistência e conflito, os aspectos e elementos do eu e do mundo implicados nessa interação modificam a experiência com emoções e ideias, de modo que emerge a intenção consciente. Muitas vezes, porém, a experiência vivida é incipiente. As coisas são experimentadas, mas não de modo a se comporem em uma experiência singular. Há distração e dispersão; o que observamos e o que pensamos, o que desejamos e o que obtemos, discordam entre si. Pomos as mãos no arado e viramos para trás; começamos e paramos não porque a experiência tenha atingido o fim em nome do qual foi iniciada, mas por causa de interrupções externas ou da letargia interna. (DEWEY, J. 2010: 108)
\end{abstract}

Neste contexto, acreditamos que a experiência desenvolvida com os projetos de trabalho ampliou noções de adaptação ao ambiente que nos rodeava. Intensificando uma interação clara entre ambiente de trabalho, ideias e relações estabelecidas.

Ao mesmo tempo, analisamos em algumas disciplinas exemplos de artistas que também atuam ou atuaram como professores. Um exemplo recorrente era o artista Joseph Beuys, que além de artista, atuava também como professor na Universidade de Dusseldorf, Alemanha, junto ao curso de Artes Plásticas. Suas aulas eram uma hibridização entre trabalhos de arte e aulas no senso consuetudinário. Suas aulas/trabalhos de arte, quase sempre no formato de lectures, abordavam a necessidade de se empodeirar a individualidade criativa enquanto uma "arma" capaz de transfazer a vida como um todo. 


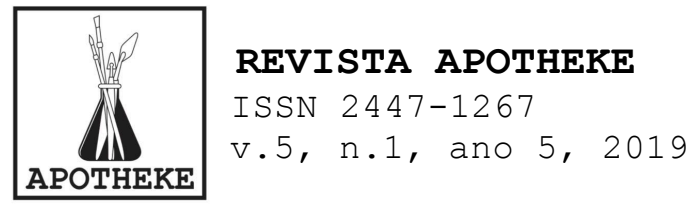

\begin{abstract}
Enquanto professor, Beuys tinha uma vida pública diária. O seu compromisso pedagógico é uma prova irrefutável da reflexão global que fez constantemente sobre o presente e o futuro e o papel que pode caber ao ser-aluno de resistir à aniquilação do humano - naquilo que nele é capacidade criadora e potência para a autonomia - risco a que se submete o indivíduo-aluno face aos valores dominantes da sociedade burguesa. (GOMES, 2011: 44)
\end{abstract}

Beuys é um claro adágio do artista/professor que tensiona relações entre arte e vida, implicando a seu processo criativo, indagações a respeito da própria arte, da educação, da filosofia, além de aspectos fluídos e interdisciplinares. Demonstrando que seu processo de criação sofria influências de sua atuação como docente e, suas aulas, eram na verdade, trabalhos de arte. De certa forma, desconstruiu a "autoridade do artista", desarticulando passo a passo o complexo jogo dorsal do sistema artístico. Enquanto artista/professor, problematizou a ideia de autoridade, enfrentando diretamente o conceito de soberania enquanto regulador de sociabilidades. O papel comum do artista/professor deixa de fazer sentido após as atuações de Beuys. A partir dele, a posição do ser artista/professor, não pode ser outra que não um ser livre, híbrido e contestador.

O conceito de "Freie Universität", aberta e disposta a receber a todos, sem limitar aspectos como formação, cobrança de mensalidades, burocracias e hierarquias, onde se fazia uma gestão colaborativa, e que o próprio Beuys declarava que cada professor era um aluno e que cada aluno era um professor, demonstra esse embate com a soberania, um afrontamento da ordem da arte, mas também do social e do político. Seus trabalhos, identificados pelo próprio artista como ações, ocorriam, em alguns casos, de forma independente do circuito da arte, eram realizados em escolas com a participação de alunos ou em praças com a participação da comunidade. 


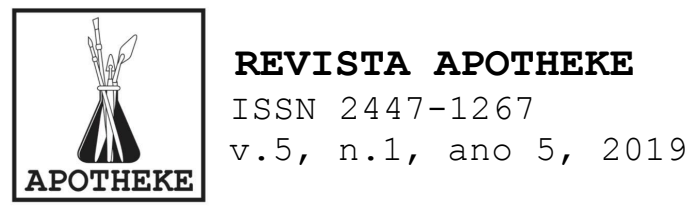

Um exemplo, dos mais notórios é a intervenção öÖ-Programm (1967), realizada na Academia de Belas Artes de Düsseldorf, onde, em uma recepção aos novos alunos, durante uma solenidade, quando lhe competia discursar aos estudantes, o artista/professor apropriando-se do microfone e empunhando um machado, emitiu urros e sons irreconhecíveis por dez minutos aproximadamente, causando sério desconforto na cúpula acadêmica da universidade que dividia o mesmo palco. Ao transformar um momento solene da academia em um evento "absurdo", Beuys transforma e enfrenta o conceito de autoridade, demonstrando que como professor e articulador da arte num ambiente acadêmico, estava a seu alcance criar, performar o ser artista perante a tirania da autoridade global.

\begin{abstract}
Ao mergulhar a academia numa atmosfera absurda, desconstruindo o evento formal, Beuys deliberadamente escarnece do poder oficial e põe em causa a autoridade de quem dispõe do palco do discurso. O machado que carrega na mão personifica o poder, remetendo-nos para o atributo da autoridade dos guardiões dos cônsules romanos. Não é de todo inverosímil estabelecer este paralelo sabendo que a origem etimológica do termo fascismo procede da palavra fasces, que designava as varas que envolviam o machado, símbolo de poder no império Romano. (GOMES, 2011: 48)
\end{abstract}

A partir de 1970, Beuys inicia as ditas "pädagogische Vorträge" proclamadas como ações performativas, onde a ação do artista se registrava em quadros negros de sala de aula amplamente grafados com giz. Os quadros que hoje podem ser vistos no Hamburger Bahnhof Museum em Berlim, eram definidos por ele como elementos de um debate permanente, e juntos constituíam uma espécie de "didaktische Installation". As aulas-performance versavam sobre diversos temas, no entanto, entre os mais frequentes surgiam itens que pairavam entre arte, vida e política. 


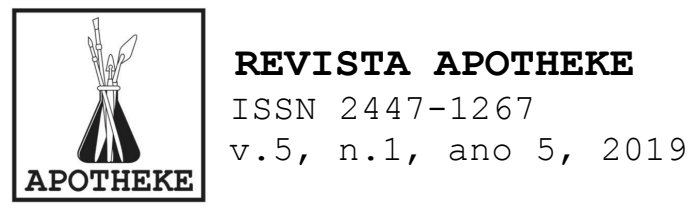

O método herético aplicado pelo artista no ambiente universitário, transformava a conferência entre professor e aluno, num mergulho com a arte. Segundo Gomes (2011), Beuys declarou inúmeras vezes: "Ser professor é minha grande obra de arte". E no ambiente de ensino talvez tenham se forjado algumas das mais impactantes ações artísticas de Beuys.

Por este caminho, é possível perceber que a atuação do artista/professor em uma escola é fundamental, seja ela de qualquer grau, pois o artista além de se preocupar com questões específicas da própria arte, pode, quando lhe couber e, se lhe couber, transitar livremente entre arte, vida, política e sociedade. Pois é dever da arte questionar, transformar e reverberar sentidos antes calados. Beuys não seria o único exemplo para esta reflexão, mas é talvez um dos mais significativos quando pensamos na possibilidade de fluidificar o papel do artista e do professor, onde suas aulas, concorridas muitas vezes entre mais de 400 alunos, realizadas de portas abertas e de acesso livre, se transformavam em ações ou performances, dificultando saber se - conteúdo de ensino havia se transformado em obra, ou se a obra havia se transformado em conteúdo de ensino.

Muitas destas questões surgiram durante disciplinas como - ateliê de pintura ou ateliê livre de criação. Além das discussões em torno do ser artista/professor, também pensávamos a posição da pintura e do desenho enquanto linguagens possíveis ainda hoje, considerando a realidade da arte post-medium, por exemplo. Nestas discussões se fortificavam olhares críticos, processos de pesquisa, construção e diálogo com outras obras, pensadores e artistas. Refletir e questionar eram partes essenciais dos projetos de trabalho, onde a experiência do artista/pesquisador contribuía inegavelmente para o desenvolvimento didático/pedagógico. 


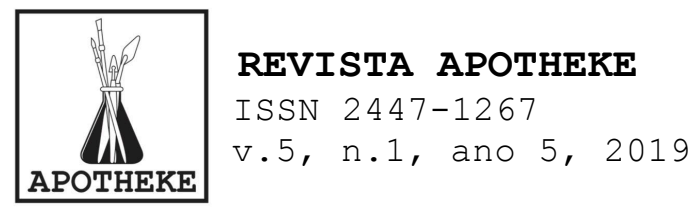

Por fim, podemos retornar a questão formulada no começo deste ensaio: Mas o que move o artista a transitar entre a criação e o ensino? Independente de diversas razões ou dilemas pessoais que levam o indivíduo a esta encruzilhada, ousaria refletir, que todo o artista é um educador, independente se atua ou não na educação formal ou informal, pois toda e qualquer operação artística é capaz de engendrar conhecimento, é sintoma de liberdade e geradora de transformações. Ensinar e criar são ambas atuações sociais, onde uma alimenta a outra, e cria-se um caminho de mão dupla. De um ponto de vista particular, junta-se o profissional artista ao profissional professor, e nesse meio, ampliam-se complexidades, formando um terceiro ser. Este tema, em amplo debate, pode e deve encontrar inúmeras reflexões, e divergentes pontos de encontro. Possivelmente não há uma resposta clara sobre esta problemática, pois não devemos apenas nos deter em problemas identitários, pois existem ainda inúmeras dificuldades de leitura que esta hibridização pode incutir.

\section{REFERÊNCIAS :}

ALMEIDA, B. P. A Impossibilidade de Ensinar Arte é a Realidade que Funda Uma Escola de Arte. IN: Pensar o Fazer da Pintura - 31 Teses sobre o investigar e criar em pintura. FBAUP, Porto: 2017

DEWEY, John. Arte como Experiência. Tradução de Vera Ribeiro. São Paulo: Martins Fontes, 2010 .

GOMES, J. Beuys Homem-Arena. In BEUYS, J. (2011). Cada homem um artista. 7 Nós, 2011.

HERNÁNDEZ, F. Transgressão e Mudança na Educação. Os Projetos de Trabalho. Porto Alegre: Artmed, 1998.

HERNÁNDEZ, F. ; VENTURA, M. A Organização do Currículo por projetos. O Conhecimento é um Caleidoscópio. Porto Alegre: Artmed, 1998 .

KRAUSS, R. A Voyage on the North Sea: Art in the Age of the Post-Medium Condition. Disponível em:

https://artecontemporaneaeahc.files.wordpress.com/2016/10/krauss voyage-onthe-north-sea.pdf acesso 05/03/2019. 


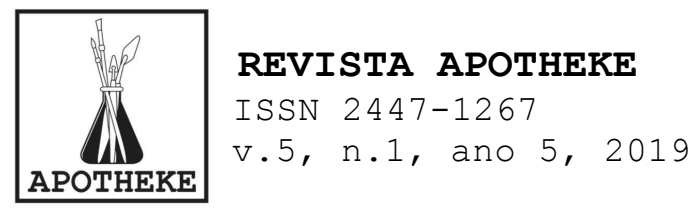

REIS, C. N. B. A.; SANTOS, P. C.; FRIQUES, M. S. Arte e Política em Joseph Beuys: o Homem como obra de arte. REDIGE SENAI. 2013. Artigo disponível em:

https: / / www.researchgate. net/publication/321775809 Arte e Politi ca_em_Joseph_Beuys_o_Homem_como_obra_de_arte acessado em $\overline{28 / 02 / 2019 .}$

SOUSA, D. M. C. de. A Experiência do Professor-Artista.

Dissertação de Mestrado em Educação Artística. Repositório

digital Universidade de Lisboa. Disponível em:

http://repositorio.ul.pt/bitstream/10451/33693/2/ULFBA_TES1117_D ALILA_Dissertacaoo20Final.pdf acesso 05/03/2019.

\section{André Luiz Rigatti}

http://lattes.cnpq.br/6033404427169836

Artista plástico e professor. Doutorando em Artes Plásticas pela Faculdade de Belas Artes da Universidade do Porto, Portugal. Mestre em Artes Visuais pela Universidade do Estado de Santa Catarina UDESC (2012). Bacharel em Artes Visuais pela Universidade Tuiuti do Paraná (2005). Professor no curso de Licenciatura em Artes Visuais da Universidade Federal de Rondônia - UNIR em Porto Velho RO. 